\title{
0 internato rural $e$ a formação de estudantes do curso de Odontologia da UFMG
}

\author{
Thalita Thyrza de Almeida Santa-Rosa ${ }^{1}$ \\ Andréa Maria Duarte Vargas ${ }^{2}$ \\ Efigênia Ferreira e Ferreira ${ }^{2}$
}

SANTA-ROSA, T.T.A.; VARGAS, A.M.D.; FERREIRA, E.F. Rural internship and the formation of dental students at UFMG. Interface - Comunic., Saúde, Educ., v.11, n.23, p.451-66, set/dez 2007.

This paper aimed at asserting the influence of Rural Internship in the formation of dental students at UFMG (Minas Gerais Federal University). Based on qualitative methodology, data collection used the focus group technique. Sample size was of fifteen students who participated in groups before and after concluding the discipline. Following data analysis, four major themes emerged: expectations regarding Rural Internship; its unfolding process; public health service; and understanding the health and disease process. It was concluded that Rural Internship was seen as a transition between academic and professional lives; that little attention given to social sciences and the public health service in previous undergraduate terms made insertion of students in the health service harder; that population's low living standards and the existence of an organized and efficient health system were greeted with surprise by the students; and that experiences undertaken during internship had waken them to patient attention based on warm welcome and health care.

KEY WORDS: Rural Internship. Dental Education. Dental students.

Analisa-se a infuência da experiência do Internato Rural (IR) na formação de estudantes de Odontologia da UFMG. Baseando-se em metodologia qualitativa realizou-se coleta de dados utilizando-se técnica de grupo focal. A amostra constituiu-se de quinze estudantes que participaram dos grupos antes e após conclusão da disciplina. No tratamento dos dados emergiram quatro grandes temas: expectativas e realização do IR, serviço público de saúde e compreensão do processo saúde-doença. Concluiu-se que o IR é visto como transição entre vida acadêmica $e$ mundo profissional; que a pouca ênfase dada às ciências sociais e ao serviço público de saúde durante períodos anteriores da graduação dificultou a inserção dos estudantes no serviço de saúde; que as precárias condições de vida da população e a existência de serviços públicos de saúde organizados e resolutivos no nível básico foram constatadas com surpresa pelos estudantes, e que experiências vivenciadas no IR despertaram para atendimento pautado no acolhimento e cuidado à saúde.

PALAVRAS-CHAVE: Internato Rural. Ensino de Odontologia. Estudantes de Odontologia.

\footnotetext{
* Elaborado a partir de Santa-Rosa, 2005.

${ }^{1}$ Cirurgiã-dentista; mestre em Odontologia em Saúde Coletiva; professora, Departamento de Odontologia, Universidade Estadual de Montes Claros (UNIMONTES). Montes Claros, MG. <thalitasantarosa@yahoo.com.br>

${ }^{2}$ Cirurgiãs-dentistas; doutoras em Epidemiologia; professoras, departamento de Odontologia Social e Preventiva, Faculdade de Odontologia, Universidade Federal de Minas Gerais (UFMG). Belo Horizonte, MG. vargasnt@task.com.br; <efigenia@uai.com.br>
} 


\section{Introdução}

A implantação do Sistema único de Saúde (SUS) no contexto socioeconômico e político brasileiro constitui grande desafio e está diretamente vinculada à formação e capacitação de recursos humanos em saúde. Nesse cenário, o Ministério da Saúde e o Ministério da Educação têm enfatizado a importância da reformulação do ensino superior brasileiro, visando adequá-lo às necessidades do país e, portanto, ao SUS, preconizando um novo perfil de profissional da área de saúde. Segundo as Diretrizes Curriculares Nacionais (DCN) para os Cursos de Odontologia, tal perfil caracteriza-se pela formação generalista, humanista, crítica e reflexiva, que capacite o profissional a atuar em todos os níveis de atenção à saúde, com base no rigor técnico-científico, e dirigindo sua atuação para a transformação da realidade em benefício da sociedade (Brasil, 2002).

Como estratégia para essa mudança, o Conselho Nacional de Educação (CNE), a Câmara Superior de Ensino (CSE) e entidades de ensino superior, como a Associação Brasileira de Ensino Odontológico (ABENO), preconizaram a instituição de um estágio supervisionado obrigatório para a conclusão do curso de Graduação em Odontologia, bem como definiram diretrizes e parâmetros para sua implantação (Associação Brasileira de Ensino Odontológico, 2003).

O projeto pedagógico da Faculdade de Odontologia da Universidade Federal de Minas Gerais (FOUFMG), concebido na última reformulação curricular da faculdade, em 1992, portanto bem antes da definição das DCN, apresenta, como eixo estrutural, cinco disciplinas clínicas de atenção primária (CIAP-Clínica Integrada de Atenção Primária), do $4^{\circ}$ ao $8^{\circ}$ período de graduação, e o Internato Rural (IR), no $9^{\circ}$ período. Complementando este eixo, existem as disciplinas clínicas das diversas especialidades que compõem a atenção secundária. As CIAPs são a porta de entrada do sistema (assim como no serviço) e os pacientes são encaminhados pelo SUS, por meio de convênio da prefeitura de Belo Horizonte com a faculdade. Nessas clínicas, o aluno elabora um diagnóstico integral do paciente, realiza os procedimentos primários em saúde bucal e os encaminha para as clínicas de atenção secundária (especialidades), quando necessário. O Internato Rural tem como objetivo possibilitar ao estudante uma vivência concreta do SUS e a aproximação com a realidade socioeconômica-cultural da população uma vez que sua prática é extramuros, integrada à comunidade e ao serviço de saúde local.

Apesar de esse modelo curricular ter sido considerado inovador para a época, as abordagens pedagógicas apresentadas pelas várias áreas e disciplinas nem sempre seguiram a mesma linha, uma vez que são os professores que definem como vão ensinar, e a metodologia hegemônica ainda é a tradicional.

Com uma carga horária de 315 horas, o IR apresenta objetivos e metodologia coerentes com as diretrizes fixadas para o estágio obrigatório, sendo a única disciplina da atual grade curricular a ofertar um outro cenário, isto é, outro local de prática profissional que não seja intramuros. As atividades teóricas abrangem conteúdos como: evolução das políticas públicas de saúde no mundo e no Brasil, o Sistema único de Saúde, políticas de saúde bucal, epidemiologia, fundamentos de ciências sociais, gestão e gerenciamento de sistemas e programas de saúde, administração e planejamento de ações e serviços de saúde bucal, sistemas de saúde bucal e integração docência/serviço, sempre desenvolvidas sob a forma de Grupos de Discussão (GD), no próprio local de prática. Essa atividade prática é 
realizada em municípios do interior do estado ou na região metropolitana de Belo Horizonte e, por manter a relação de uma dupla de alunos por professor supervisor, com encontros quinzenais, possibilita a prática de novas abordagens pedagógicas (FOUFMG, 2003).

O grupo de professores responsáveis pelo IR procurou planejá-lo utilizando princípios pedagógicos que possibilitassem aos estudantes a conquista de competências e habilidades previstas nas DCN (Brasil, 2002), como capacidade de tomada de decisões, comunicação e liderança, entre outras.

O respeito à autonomia do aluno foi preocupação do grupo de professores desde o início da oferta desta disciplina, pois os docentes têm tentado trabalhar com base em fundamentos teóricos de Paulo Freire. Esse autor, ao criticar os métodos educativos, refere-se ao "inacabamento" do ser humano e à necessidade da total conscientização sobre esse fato para se conseguir respeitar a autonomia do educando. Freire (2001) coloca esse respeito como um imperativo ético, e não um favor que pode ou não ser concedido. Considera que o posicionamento contrário (do educador) pode trazer sérios impedimentos à rebeldia legítima, caminho seguro para a construção do conhecimento.

Outro fundamento que orienta os professores do IR é o Relatório para a Unesco da Comissão Internacional sobre Educação para o Século XXI, coordenado por Jacques Delors (Unesco-MEC, 1999). Segundo esse relatório, a educação deve se fundamentar em quatro pilares, denominados pilares do conhecimento: aprender a conhecer, aprender a fazer, aprender a viver juntos e aprender a ser. Segundo o mesmo relatório, os quatro pilares formam apenas um, em função da inter-relação existente entre eles: aprender a aprender.

Deve-se ressaltar que outras equipes de professores da FOUFMG, sobretudo os lotados na CIAP, têm se preocupado em usar métodos educativos mais eficientes, por exemplo: utilizando a metodologia problematizadora para solução de casos, para compreensão do processo de atendimento clínico, para a importância da demanda colocada pelos pacientes (necessidade subjetiva), trabalhando os mesmos fundamentos teóricos, porém, com desenvolvimento restrito às dependências da FOUFMG. No dizer de Costa et al. (2000), a aproximação com a comunidade, permitida por atividades que extrapolam os limites físicos da Faculdade (extramuros), possibilita o rompimento com a formação individualista e tecnicista da profissão odontológica.

O objetivo do presente trabalho foi conhecer e analisar como a experiência de aproximação com a realidade da população pode contribuir para a formação de estudantes de graduação, durante o Internato Rural.

\section{Metodologia}

Optou-se por utilizar a metodologia qualitativa $e$ a coleta de dados do estudo foi realizada no período de janeiro a outubro de 2004. O grupo focal foi a técnica escolhida porque permite a troca de experiências, pontos de vista e idéias.

Estimula os participantes a gerarem seus próprios questionamentos e a desenvolverem sua própria análise das experiências em comum (Kitzinger, 1996).

O universo do presente estudo foi constituído pelo grupo de estudantes do último período do curso de Odontologia da UFMG que participou do Internato Rural. O grupo de voluntários foi constituído por 15 estudantes, com idade média 
de 23,7 $( \pm 1,4)$ anos, sendo dez mulheres e cinco homens, os quais foram divididos em três subgrupos de cinco alunos.

As discussões dos grupos focais, todas gravadas em fitas cassete, foram realizadas em dois momentos. O primeiro momento foi anterior à realização da disciplina IR, sendo enfocadas questões sobre saúde, doença, serviço público $e$ expectativas quanto ao Internato. Ao término da disciplina, realizou-se o segundo encontro, quando foram discutidas as experiências vividas, as possíveis mudanças na percepção de saúde e doença, e a vivência dentro do Serviço Público de Saúde. Todos os estudantes participaram dos dois momentos. Para orientar o discurso foi utilizado um roteiro elaborado à luz dos objetivos do estudo e respaldado na revisão bibliográfica. O roteiro foi previamente ajustado por meio de pré-teste, também realizado na forma de grupo focal, com quatro estudantes não incluídos no estudo principal.

Obteve-se a autorização dos participantes mediante assinatura de "Termo de Consentimento Livre e Esclarecido". O Projeto de Pesquisa foi submetido ao Comitê de Ética em Pesquisa da UFMG e aprovado com o parecer número ETIC 022/04.

As falas dos voluntários foram transcritas pela própria pesquisadora. Os dados colhidos foram analisados e interpretados de acordo com metodologia proposta por Minayo (2004). Após leitura exaustiva, o material transcrito foi organizado de acordo com os temas abordados. Esta seleção dos temas foi realizada por três pesquisadoras, simultânea $e$ independentemente, com o intuito de permitir diferentes enfoques e abordagens do material. Essa forma de tratar os dados permitiu uma análise mais cuidadosa. (Denzin, 1978, citado por Hudelson, 1994)

\section{Resultados e discussão}

Quatro grandes temas emergiram durante o tratamento dos dados: expectativas acerca do Internato Rural, realização do Internato Rural, o serviço público de saúde e compreensão do processo saúde-doença.

\section{Expectativas acerca do Internato Rural}

Durante os grupos focais iniciais, percebeu-se a ansiedade dos estudantes com o início da disciplina IR. A possibilidade de conhecer pessoas, fazer novas amizades, conviver com pessoas diferentes numa mesma casa, além do certo distanciamento $e$ independência da família, foram relatos freqüentes.

É uma independência completa, como se fosse gente grande mesmo, tanto como profissional quanto como adulto assim, na sua própria casa.

(...) nunca saí de casa, nunca morei fora de casa, acho que vai ser legal (...) de se virar, de conviver com pessoas diferentes (...)

Os estudantes vêem, na possibilidade de serem os responsáveis por todas as etapas do tratamento odontológico, do planejamento até a finalização, a oportunidade de executar, na prática clínica, autonomamente, o que foi aprendido e executado nos períodos anteriores. A presença constante do professor durante as aulas 
clínicas do curso de graduação parece inibir os estudantes, gerando um sentimento de insegurança e incapacidade de solucionar problemas. O IR é visto como a oportunidade de libertar-se e tornar-se independente .

Aqui a gente aprendeu toda a parte teórica, lá que a gente vai botar em prática. Vai ser muito bom pra gente, a gente vai aprender demais.

Muitas vezes aqui dentro da Faculdade a gente está preso aos professores e agindo sob as ordens dele (...). Lá a nossa atitude vai influenciar diretamente, não vai ter ninguém pra corrigir.

O anseio de se sentir autônomo, sendo o responsável pelo paciente e ficando longe da presença do professor, parece descortinar a realidade vivida durante grande parte dos períodos anteriores da graduação, onde muitos professores seguem o lema de "o professor manda e o aluno obedece", perpetuando o modelo do professor repassador de conhecimento, como denomina Masetto (1998), enquanto a postura, segundo Freire (2001), deve ser a de um facilitador e incentivador no processo de ensino-aprendizagem. $O$ modo de agir tradicional em nada contribui para a formação do perfil profissional preconizado pelos Ministérios da Educação, Ministério da Saúde e pela ABENO: um profissional com formação crítica e reflexiva.

\footnotetext{
(...) você abre um sorriso e concorda, mesmo que você discorde: não discuta. Pronto e acabou! Se você for discutir vai fazer a besteira de ser marcado (...) Os professores querem que você seja um filhotinho deles, você tem que seguir essa doutrina porque essa é a certa, mas não é a certa, entendeu? (...) lá (Internato Rural) a gente vai ter mais liberdade de escolher (...).
}

Somem-se a isso as possibilidades pedagógicas facilitadas pelo cenário de prática do IR e pela própria organização da disciplina, que prevê a presença do professor supervisor, quinzenalmente, no período de oito horas, aproximadamente.

De acordo com as falas dos estudantes, percebeu-se que outro ponto que julgam importante na realização do IR é a possibilidade de aprenderem a trabalhar em atividades coletivas com as comunidades, de entrarem em contato com uma realidade e de fazerem um tipo de atendimento diferente do vivenciado nas atividades intramuros. Ao exprimirem essas expectativas, os estudantes relataram que, até o oitavo período, a formação é voltada apenas para o atendimento individual do paciente, $e$ as atividades coletivas só são realizadas por estudantes que participam de projetos de extensão voltados para atividades educativas em saúde. O IR vem proporcionar um trabalho em saúde coletiva mais concreto, difícil de ser vivenciado durante os períodos anteriores da graduação.

Eu acho que o mais importante que eu espero do Internato é aprender Saúde Coletiva (...) porque a gente não tem uma noção muito clara disso aqui na Faculdade.

Ao se referirem às populações com as quais iriam conviver durante o IR, os estudantes esperavam encontrar muita necessidade de tratamento odontológico. 
A despeito disso, a maioria mostrou uma visão bem bucólica e idealizada da vida no interior, como se, a qualquer momento, Dirceu, o pastor das obras do escritor árcade, Tomás Antônio Gonzaga, fosse aparecer entre flores e pastagens para recitar poesias para sua amada Marília. Referiram-se ao interior como um mundo à parte, onde tudo é diferente, a população é "atrasada", o tempo passa devagar, não existe estresse.

Eu acho que eles têm a horta deles, que eles têm acesso a verduras, legumes, que a alimentação seja bem enriquecida. (...) eu vejo a alimentação deles até melhor. Eles têm um padrão de alimentação: de manhã eles almoçam e a noite eles jantam. (...) E a gente aqui come: hambúrguer, salgado... (...) por causa dessa questão da correria, da falta de tempo a nossa alimentação fica prejudicada, eles não. Eu vejo que no interior a coisa é mais calma, mais lenta...

Os estudantes responsabilizaram a falta de programas públicos que incluam a Odontologia, a falta de informação e a aceitação popular da inexorabilidade da perda dentária, pelas péssimas condições de saúde bucal que esperavam encontrar no interior. Para eles, se os pacientes soubessem dos tipos de tratamento existentes, talvez a situação fosse outra; supunham que o simples conhecimento das possibilidades fosse suficiente para reverter uma situação precária de saúde que há muito se sedimentou.

Eu tenho certeza que o que eu vou encontrar lá é desdentado à vontade (...) eu acho que é falta de informação mesmo que não chega lá; eles nem sabem que tem um tipo de tratamento (...) que existe uma ponte fixa (...).

Os estudantes mantiveram a postura de críticos e detentores do saber, recriminando a falta de importância que as pessoas de classes populares mais baixas dão à saúde bucal. Ao afirmarem que a cultura da população não vislumbra a saúde bucal como algo importante, os estudantes culpam o paciente pela sua situação bucal.

(...) este padrão de cultura que você não dá valor pro dente, arranca tudo e põe dentadura (...) O avô tem dentadura, todos os irmãos na casa têm, e vai ficar sofrendo com este dente aí? Arranca e põe uma dentadura que isso não presta, isso só vai dar sofrimento, só vai dar dor.(...) Na concepção dele a dentadura é a melhor solução para os problemas dele, não precisa complicar.

Sendo a cultura um conjunto de regras que norteia e dá significado à visão do mundo de um determinado grupo social (Víctora et al., 2000), cada grupo poderá atribuir um significado diferente a esse ou àquele fenômeno, mas os estudantes enxergam apenas o seu ponto de vista como certo e aceitável. Se cultura varia de um grupo para outro, não há como definir o que está correto. É provável que esse sentimento de superioridade advenha da própria formação acadêmica que, apesar dos avanços, ainda é fortemente praticada com base no modelo biomédico que, em nome da neutralidade, do tecnicismo e do cientificismo, excluiu o contexto sociocultural do processo saúde-doença (Unfer \& Saliba, 2001), reduzindo o paciente a uma máquina a ser consertada de acordo com preceitos científicos 
comprovados. O profissional detém o saber e ao paciente resta aceitar o que foi proposto.

Outra grande expectativa dos estudantes acerca do IR é conhecer o serviço público de saúde, vislumbrando uma possibilidade futura de emprego. $\mathrm{O}$ Internato Rural é a chance de conhecer, ser conhecido e de gostar do trabalho.

(...) conhecer o serviço público de saúde, porque eu acho que onde muitos dos dentistas recém formados estão tentando entrar depois de formar porque é um emprego garantido, é aquela coisa assim mais certa, ter um salário certo no final do mês. Todo mundo está tentando entrar.

\section{Realização do Internato Rural}

No segundo momento da pesquisa, com a realização do grupo focal após o término da disciplina Internato Rural, percebeu-se o entusiasmo dos estudantes com as atividades desenvolvidas, pois a expectativa de trabalhar com autonomia foi concretizada. Ao relatarem experiências vivenciadas no dia-a-dia no serviço público, os estudantes ressaltaram que foi muito importante serem responsáveis pelas decisões. Quando precisaram solucionar problemas, perceberam que tinham condições de fazê-lo.

Acho que tirou aquele medo. Aquela coisa de não sei se eu sei, entendeu? Eu passei quatro anos e meio, mas eu não sei se eu sei. Então os primeiros dias antes da gente começar a trabalhar, você fica morrendo de medo (...). Você achava que não, porque sempre tinha um professor atrás de você. Qualquer aperto era só levantar a mão...

De acordo com o $4^{\circ}$ artigo das DCN do Curso de Odontologia (Brasil, 2002), o cirurgião-dentista deve ser capaz de tomar decisões, pensar criticamente $e$ assumir posições de liderança. Bordenave (1994) ressalta que as concepções pedagógicas de transmissão e de condicionamento (aplicadas em grande parte das instituições de ensino) não contribuem para o crescimento pleno do estudante, uma vez que não lhes despertam o interesse e o prazer de aprender, nem os estimulam a desenvolver uma postura crítica diante de possíveis problemas que possam surgir. Pelas falas dos estudantes, pode-se inferir que isso não tem acontecido usualmente em sua formação acadêmica, sendo necessário que eles saiam para uma atividade extramuros para vivenciar sua capacidade de decisão e planejamento de ações.

E a gente também desenvolveu mais a nossa capacidade (...) Em todos os aspectos. Como dentista mesmo; de ter a capacidade de ter uma visão geral do indivíduo, plano de tratamento, planejar, discutir, pensar nas possibilidades.

Durante as discussões, a todo momento, os estudantes afirmaram que o IR foi ótimo, que foi uma experiência marcante, que aprenderam muito, amadureceram bastante, mas que o mais importante foi o "crescimento pessoal". A disciplina mostrou ser capaz de extrapolar o aprender a conhecer e o 
aprender a fazer, possibilitando também o aprender a viver juntos e aprender a ser (UNESCO-MEC, 1999).

O ganho pessoal do Internato é muito maior que o profissional, com certeza! (...) você entra na Faculdade um adolescente ainda. Você está na profissão, você formou e você não caiu na real que já está velho, que você já é adulto. Na hora que você vai para o Internato, é que você tem que tomar suas atitudes: como pessoa e como profissional. Não tem mãe e não tem pai do lado. Você vê lá que já é um adulto, eu sou um profissional, você acorda.

Mais uma vez, o IR é entendido como um momento de transição, de passagem entre a falta de preocupação adolescente e o peso da responsabilidade de entrar no mundo profissional e adulto. Pode-se dizer que o período do Internato está para os estudantes assim como os óculos para Miguilim. Este personagem de João Guimarães Rosa era um menino míope, que via o mundo embaçado e acreditava que aquilo era o real. Certo dia, ao colocar uns óculos emprestados, Miguilim enxergou o mundo com nitidez. Esse momento simboliza o crescimento, um rito de passagem, no qual enxergar mais nitidamente o mundo significa entrar para a fase adulta (Guimarães Rosa, 2001).

Apesar do pouco tempo, as experiências vividas no IR são relatadas como inesquecíveis, seja pelo "crescimento profissional", seja pelo "crescimento pessoal". A possibilidade de vivenciar um "eu" que parecia estar sufocado pela faculdade $e$ pela família parece ter possibilitado a concretização desse "rito de passagem".

Entre os ganhos do IR, os estudantes relataram ter aprendido a cozinhar, arrumar casa, tocar violão, dirigir, tomar decisões sozinhos, conviver com outras pessoas, conhecer outras culturas. Para alguns estudantes, aprender a conversar $e$ escutar os pacientes foi um dos maiores ganhos, denotando que isso não ocorre, rotineiramente, na prática clínica da FOUFMG.

(...) pra mim foi o relacionamento com pessoas mais humildes, nesse sentido de saber escutar mais as pessoas.

No discurso dos estudantes observou-se uma separação bem marcada entre crescimento profissional e pessoal, aludindo à profissão apenas sobre o caráter técnico e restrito à cavidade bucal, enquanto o nível pessoal relaciona-se a conviver com as pessoas, a conhecer outras realidades, a sentir-se independente dos pais e dos professores. O limite entre o pessoal e o profissional é bem definido, sugerindo que a ênfase dada à técnica e a neutralidade científica, tão propaladas $e$ arraigadas na formação acadêmica, determinaram um discurso marcado pelo distanciamento entre o pessoal e o profissional.

Apesar da separação pessoal/profissional, à qual os estudantes freqüentemente se reportaram, apreendeu-se que, no IR, essa dicotomia foi apenas conceitual. Durante o contato com as populações, os estudantes criaram laços afetivos que remeteram a preocupação, solidariedade e cuidado. Mostraram-se extremamente tocados e sensibilizados com a atenção com que foram recebidos pela população. $\mathrm{O}$ estabelecimento de vínculo foi facilitado, em função do cenário de prática que, no IR, possibilitou o "estar junto" ou "viver junto". 
(...) tinha um senhor que, nossa, que gracinha! Que saudade! Tratava a gente super bem, eu me sentia neta dele.

Ao estabelecerem vínculos com as comunidades, deslocaram o foco da atenção do atendimento baseado na racionalidade das ciências biomédicas para um atendimento centrado no usuário, pautado no cuidado em saúde. Para Ayres (2000), a noção de cuidado, ao remeter à preocupação em promover saúde, ao contrário de apenas corrigir distúrbios, traz para a assistência a aspiração por saúde dos indivíduos e populações, humanizando o atendimento.

(...) muitas vezes o que a gente sentia nos próprios pacientes é que eles precisavam de carinho, sabe? (...) Está precisando muito é de carinho, de atenção... Precisa também de tratamento, é claro, mas um pouquinho que você conversa (...) É só atender com carinho. Necessitavam, precisavam de muito carinho.

As falas dos estudantes evidenciam que o IR parece ter contribuído para a formação de um profissional voltado não apenas para a técnica operatória, como também para as necessidades $e$ anseios do paciente.

A visão idealizada que os estudantes tinham da vida no interior parece ter sido substituída pela realidade. As condições precárias de vida, citadas apenas superficialmente no primeiro encontro, foram um dos pontos fortes da discussão no segundo momento da pesquisa. Os estudantes mostraram-se impressionados com as péssimas condições de vida das populações de algumas localidades: falta de saneamento, falta de dinheiro, falta de estrutura física. Para eles, era impossível conceber que alguém conseguisse sobreviver naquelas condições.

A gente não tem muita noção disso, né? No nosso atendimento aqui, a gente pega gente com muitas necessidades, só que lá eu achei demais. Fora do que eu imaginava mesmo. Muito triste a situação.

Paixão (1979), há mais de duas décadas, já chamava a atenção para o distanciamento entre a faculdade e a realidade da população e via nisso uma falha na formação do futuro profissional. Hoje, os conteúdos ensinados ainda persistem desconectados da realidade nacional, apontando para uma falta de integração entre o ensino e os problemas de saúde da população, como pode ser observado nas falas dos estudantes:

Pegamos um pessoal para atender que mora muito longe, atravessava a BR $e$ subindo, dava mais de meia hora de caminhada, num sol de três horas. (...) faziam a extração e eles voltavam a pé (...)

A participação do orientador é essencial para o bom andamento do Internato Rural. Durante a participação em algumas reuniões de supervisão do IR, pôde-se constatar a vontade dos orientadores em despertar o espírito crítico nos estudantes, levando-os não só a questionar a realidade e seus problemas, mas também a buscar e propor soluções. A problematização, técnica utilizada por esses professores - melhor seria chamá-los de facilitadores - segundo Mamede et 
al. (2001), contribui com o desenvolvimento de um pensamento crítico, permitindo, assim, que os estudantes construam o seu próprio conhecimento.

\section{Serviço Público de Saúde}

Nos grupos focais anteriores às atividades do IR, ao se referirem ao serviço público de saúde, os estudantes falaram sobre possíveis dificuldades e limitações que esperavam encontrar. Falaram sobre "fazer o melhor possível dentro das possibilidades", em "se virar", "dar um jeitinho", denotando a idéia que tinham do serviço público: um serviço limitado, de baixa qualidade, um serviço pobre para pobres. Esperavam encontrar material de baixa qualidade ou, até mesmo, não encontrar material suficiente para a quantidade de atendimento clínico exigida pela prefeitura. O Sistema único de Saúde era visto como antítese daquele preconizado na Constituição Federal. Os estudantes faziam um paralelo entre o SUS ideal e o SUS real. O SUS real foi sempre relacionado com a inoperância, filas, greves, funcionários desinteressados, desorganização, exclusão.

Uma das grandes surpresas dos estudantes no IR foi encontrar um serviço público diferente do que esperavam. Ao contrário da visão caótica $e$ desorganizada relatada no primeiro encontro, os estudantes descreveram experiências vivenciadas em serviços que dão certo, são organizados, funcionam, atendem a população, dispõem de equipamentos e materiais de qualidade, no nível de atenção básica.
(...) porque eu imaginava que era aquilo mesmo que eu falei: uma bagunça, fila, o povo não sendo atendido e aquela confusão toda e quando a gente chegou lá eu vi que não é. Que tem um planejamento, (...) uma agenda que funciona, a gente participava das reuniões, a gente decidia junto com a equipe (...). Eu achei que funciona sim!

No entanto, a deficiência da atenção secundária no serviço público de saúde despertou certo sentimento de impotência nos estudantes. Os estudantes depararam com situações limítrofes nas quais a necessidade do paciente e a falta de recursos disponíveis (serviço especializado) os levaram a questionar seus próprios princípios e condutas. De acordo com seus relatos, devido à deficiência ou, na maioria das vezes, inexistência de atenção secundária nos serviços de saúde bucal, por diversas vezes viram-se obrigados a realizar extrações em dentes passíveis de tratamento conservador, restaurando, como afirma Iyda (1998, p.138), "a normalidade (não sentir dor), mas instaurando a anormalidade (não ter dentes)", transferindo o problema da dor para a ausência dentária, contribuindo, assim, para o incremento do componente "dentes perdidos" nos índices brasileiros. O sistema público de saúde mostrou-se perverso e contrário aos seus próprios princípios de integralidade e eqüidade ao se furtar, entre outros casos, à oferta de serviços de próteses ao usuário, após tê-lo submetido ao único tratamento disponibilizado para sanar a sua dor: a extração dentária.

Em alguns pontos a gente sentiu limitações do próprio SuS. Situações que você poderia salvar um dente ou fazer certo tratamento, mas tinha certa limitação, $e$ isso te deixa um pouco desanimado (...) 
Como dito anteriormente, a possibilidade de aprimorar a prática clínica, que era uma das maiores expectativas dos estudantes antes de iniciarem a disciplina, foi concretizada. Os estudantes declararam ter encontrado, no serviço público de saúde, a oportunidade para trabalhar muito e treinar bastante, mas que um dos maiores ganhos do IR foi perceber que só atendimento clínico não basta para resolver os problemas de saúde da população, e que existem outras formas de atuação do dentista que não seja a intraconsultório.

(..) eu acho que o ganho maior que a gente teve no internato foram as atividades diferentes da prática clínica. A gente foi pras escolas, teve contato com as professoras, com os alunos, fazia teatro de fantoches(..) e outras coisas que não são diretamente ligadas à odontologia mas que também faziam parte da saúde geral da pessoa.

A interação com outras áreas (sobretudo IR de medicina e enfermagem) foi vista pelos estudantes como uma grande oportunidade para aumentar os conhecimentos, trocar experiências e crescer profissionalmente. Relataram que a dificuldade de trabalhar com os grupos operativos (política do Ministério da Saúde), como o da hipertensão ou da diabetes, foi superada com a ajuda de estagiários de outras áreas. Questionaram a formação da FOUFMG que, até o oitavo período, é voltada apenas para o atendimento individual, desconhecendo a prática para o coletivo. Para Alves (2003), o modelo assistencial vigente no Brasil traz desafios importantes para as universidades no que diz respeito à formação de recursos humanos adequados à proposta de trabalho. Há que se repensar o ensino, procurando romper com o modelo de formação pautado no tratamento da dor e no atendimento individual, o qual forma um profissional que, segundo Paixão (1979, p.110), "se centra no aspecto curativo, na super especialização, na sofisticação, na pouca cobertura, resultando disso tudo sua incapacidade de resolver a problemática de saúde dental da população". O Ministério da Educação preconiza a formação de profissionais capacitados tecnicamente e conscientes de sua importância social na promoção de saúde e prevenção de doenças, tanto no nível individual quanto no coletivo (Brasil, 2002), o que reforça a necessidade de serem apresentadas aos acadêmicos, desde os períodos iniciais, atividades semelhantes às vivenciadas no IR; assunto já em discussão nas atividades da nova reformulação curricular, em andamento. Para os estudantes, $o$ trabalho em equipe permitiu um atendimento mais humano e integral do paciente.

\section{Compreensão do processo saúde-doença}

Durante os grupos iniciais (anteriores à realização do IR), ao abordar o tema saúde, percebeu-se certa confusão e dificuldade na verbalização das respostas. Os estudantes apenas afirmavam que saúde dependia de fatores culturais, sociais e econômicos, falando com tal cadência que pareciam ter-se lembrado do conceito de saúde da Organização Mundial de Saúde. Após o momento inicial de tentativas de conceituar saúde, os estudantes passaram a se valer de exemplos hipotéticos el ou do cotidiano para explicar saúde, revelando um abismo, um distanciamento bem marcado entre "saúde pra mim" e "saúde pra população". 
(...) pra mim, (...) é todo um aglomerado de fatores, não só saúde física, saúde mental, você estar alegre, estar feliz, de bem com a vida, vamos dizer assim. (...) você ter mais tranqüilidade pra viver a vida sem muita preocupação. Você ter seu trabalho, estar feliz no seu trabalho, seu emprego, tudo isso é saúde! Bem-estar psíquico, físico...

(...) saúde pra eles é não ter dor de dente. Conseguindo trabalhar, “tá beleza!” Tá com bafo? tudo bem, se não está doendo, tá ótimo!

A visão da população acerca do que é saúde era vista pelos entrevistados como errada, como fruto de ignorância e falta de informação. Diante disso, eles, como detentores do saber correto, ensinariam à população "hábitos e prioridades corretas". Foi possível notar que "ensinar" à população era simplesmente fazer com que o paciente aceitasse o que julgavam correto, perpetuando, assim, a distância entre profissional (que detém o poder conferido pelo conhecimento científico) e o paciente (que não conhece ou não entende esse conhecimento), distanciamento no qual a atitude e a forma de agir do primeiro modifica-se de acordo com a classe social do segundo (Boltanski, 1994).

Sobre esse assunto, Bosi e Affonso (1998) afirmam ser a ausência de dor o único critério que um indivíduo que não possui conhecimento científico pode usar para definir saúde. Assim sendo, não é a percepção de saúde da população que é incorreta, o erro está em querer que essa população defina saúde dentro dos padrões ditos científicos.

No segundo momento da pesquisa (após a realização do IR), constatou-se que a dicotomia entre saúde para os estudantes e saúde para a população manteve-se. No entanto, embora tivessem como meta "passar conhecimentos" para a população acerca de atitudes corretas e, com isso, auxiliar na melhoria das condições de saúde, os estudantes depararam-se com as dificuldades econômicas, os hábitos, a cultura e as crenças religiosas. A grande diferença, no que tange a saúde e doença, parece ter sido a aceitação, por alguns, de outra possibilidade de "saúde correta". A intenção de melhorar as condições de saúde bucal das populações assistidas pelo IR se deparou, ainda, com as limitações do próprio serviço e a resignação pela perda dentária.

(...) muitas pessoas de lá achavam que extrair o dente era a solução. Eu cansei de falar que não era; que tinha outro... E às vezes a pessoa saía de lá insatisfeita. (...) Aí você pensa assim, a solução: dá pra você fazer canal e tal? Fica pensando assim: vou fazer uma PPR, que não sei o quê, mas não é bem assim. Prótese total é bem mais barata, bem mais rápida, bem mais fácil de conseguir. (...)

O sorriso sem dentes, tão comum em nossa sociedade, não deve ser visto como fruto de passividade e comodismo, como já discutido anteriormente. É um sinal da exclusão social e das precárias condições de vida da população brasileira (Brasil, 2004), que se vê obrigada a adaptar-se à falta de dentes, a despeito de possivelmente se sentir desconfortável com tal situação (Vargas, 2005). Talvez esse quadro fosse diferente se houvesse investimentos em políticas públicas de inclusão social, distribuição de rendas, promoção de saúde e disponibilização de serviços preventivos e restauradores, na medida das necessidades da população 
Diante da constatação da realidade, sucumbiram a confiança e a certeza em uma Odontologia capaz de resolver todos os problemas bucais da população. De acordo com os próprios estudantes, sua percepção acerca de saúde e doença sofreu alterações após o IR. Contudo, não se pode afirmar que essa mudança se deveu à aceitação de que existem outras realidades que determinam as escolhas, prioridades e percepções de saúde e doença, ou se houve apenas uma resignação por parte dos estudantes no que se refere ao serviço público de saúde e saúde da população. No entanto, pode-se afirmar que o IR despertou muitos questionamentos acerca do conceito saúde-doença nos estudantes. A proximidade entre o término da disciplina e a formatura impossibilita que seja discutido e melhor elaborado, com auxílio dos supervisores, o questionamento emerso com base na vivência no Internato Rural. Caberá ao profissional responder às suas próprias questões. A faculdade não se eterniza em suas vidas, mas poderá perpetuar-se na busca constante pelo saber e pelas atitudes $e$ práticas dos seus egressos.

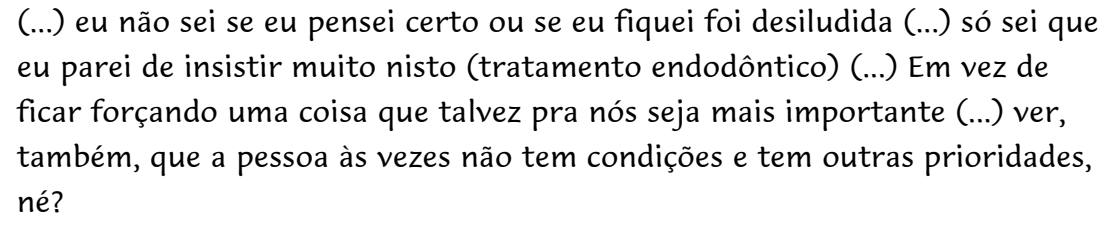

Eu acho que cada um tem um jeito de ver a saúde (...)

Durante o presente estudo, constataram-se a influência e as marcas do modelo biomédico na formação dos entrevistados. Apesar das freqüentes relações $e$ correlações que fizeram entre saúde, doença e seus vários determinantes, vez por outra se apreendeu, nas falas dos estudantes, certos traços de unicausalidade na determinação da condição bucal das populações assistidas. A ausência de flúor na água foi citada, diversas vezes, como causa óbvia da situação precária de saúde bucal da população, e a fluoretação da água do abastecimento público vista como a solução. Um elixir capaz de solucionar todos os problemas bucais da população, uma vez que "submeterá" todos ao flúor, a despeito de sua vontade, de seus hábitos, sua cultura, suas representações.

(...) principalmente pelo fato da água não ser fluoretada eles chegam com cáries extensas (...)

Contudo, a despeito de algumas limitações, o curso de Odontologia da UFMG e, sobretudo o IR, tem participado, com êxito, da formação de recursos humanos para o Sistema único de Saúde e da formação de profissionais mais críticos e preocupados com a realidade nacional (que é a filosofia do SUS), como pode ser observado na fala de um dos entrevistados:

(...) eu acho que no final das contas, foi tudo muito bom. Eu acho que tudo que a gente vê, que a gente aprende é muito bom. Entendeu? Mesmo na situação ruim da população (...). Não dá nem pra acreditar que tem pessoas 
que vivem deste jeito, sem dinheiro, sem nada. É ruim ver isto, mas é a realidade que a gente tem, que é obrigado a enxergar, aprender que o país está assim e que a gente tem que tentar mudar isto!

\section{Considerações finais}

Os dados obtidos no presente trabalho, por meio da realização de grupos focais com estudantes do último período do curso de graduação da FOUFMG, permitiram apontar considerações que não têm a intenção de encerrar o assunto. Ao contrário, vislumbram o despertar para novos caminhos, possibilidades para futuros estudos e melhorias na formação acadêmica dos estudantes de Odontologia, afinal "no processo do conhecimento não há consenso nem ponto de chegada..." (Minayo, 2004, p.228).

Durante o caminho percorrido no desenvolvimento do estudo, percebeu-se que o momento do IR é sentido pelos estudantes como um momento de grandes transformações. $O$ adolescente, acostumado com o amparo da família e com limites impostos pela presença constante do professor, durante as atividades clínicas, vê-se impelido a transpor a ponte que o liga à vida adulta. Ao fazê-lo, os estudantes declararam-se mais seguros e melhor preparados para o enfrentamento de possíveis situações a que serão submetidos na nova fase de suas vidas. O IR consegue conduzi-los ao caminho do "aprender a ser".

Além da ausência do professor em tempo integral, acompanhando todos os passos das atividades, a postura dos professores do IR, respeitando a autonomia do estudante, contribuiu para as conquistas no aprendizado.

O desenvolvimento da disciplina em municípios ou postos de saúde, inserindo o estudante no serviço, demonstrou ser procedente a necessidade de novos cenários de prática para a formação do profissional de saúde.

A pouca ênfase dada às ciências sociais e ao serviço público de saúde, durante os períodos anteriores da graduação na FOUFMG, dificultou a inserção dos estudantes no serviço público de saúde nos momentos iniciais do Internato Rural.

Após a realização do Internato Rural, os estudantes mostraram-se surpresos com a constatação da existência de serviços públicos de saúde que, a despeito da ausência da atenção secundária ou terciária, funcionam, são organizados e disponibilizam bons materiais para o atendimento.

A segurança em seus próprios conceitos e a crítica contundente às percepções de saúde da população ruíram frente à constatação das precárias condições de vida dos pacientes. Após a vivência no Internato Rural, os estudantes mostraramse mais receptivos às diferentes possibilidades de percepção de saúde e doença, seja porque entenderam a existência do "componente individual" na determinação dessas percepções ou na necessidade da abordagem coletiva, seja porque se resignaram frente às limitações do sistema público de saúde e à cultura de aceitação e inexorabilidade da perda dentária.

As experiências vivenciadas no Internato Rural despertaram os estudantes para um atendimento pautado no acolhimento ao paciente e no cuidado à saúde. No entanto, enxergar a realidade não foi suficiente para sanar lacunas deixadas na graduação, muitas menos para permitir ruptura com o modelo de ensino ao qual foram submetidos na formação acadêmica da Faculdade. 
As autoras Thalita Thyrza de Almeida Santa-Rosa, Andrea Maria Duarte Vargas e Efigênia Ferreira e Ferreira participaram, igualmente, de todas as etapas de elaboração do artigo.

\section{Referências}

ALVES, C.L.R. Saúde da família. Educação Médica - UFMG. abr. 2003. Disponível em: <http:// www.medicina.ufmg.br/edump/ped/saude_familia.htm>. Acesso em: 20 jan. 2005.

ASSOCIAÇÃO BRASILEIRA DE ENSINO ODONTOLÓGICO. Diretrizes da ABENO para a definição do Estágio Supervisionado nos cursos de Odontologia. Disponível em <http://www.abeno.org.br/prop.htm>. Acesso em 6 ago. 2003.

AYRES, J.R.C.M. Cuidado: tecnologia ou sabedoria prática? Interface - Comunic., Saúde, Educ., v.4, n.6, p.117-120, 2000

BOLTANSKI, L. As classes sociais e o corpo. 2.ed. Rio de Janeiro: Graal, 1994.

BORDENAVE, J.E.D. Alguns fatores pedagógicos. In: BRASIL. Ministério da Saúde. Coordenação Geral de Desenvolvimento de Recursos Humanos para o SUS. Capacitação pedagógica para instrutor/supervisor: área da saúde. Brasília: Ministério da Saúde, 1994. p.20-6.

BOSI, M.L.M.; AFFONSO, K.C. Cidadania, participação popular e saúde: com a palavra, os usuários da rede pública de serviços. Cad. Saúde Pública, v.2, n.14, p.355-65, 1998.

BRASIL. Ministério da Saúde. Coordenação Nacional de Saúde Bucal. Projeto SB Brasil 2003: condições de saúde bucal da população brasileira 2002-2003. Brasília: Ministério da Saúde, 2004.

BRASIL. Conselho Nacional de Educação. Câmara de Educação Superior. Resolução CNE/CES 3, de 19 de fevereiro de 2002. Institui Diretrizes Curriculares Nacionais do Curso de Graduação em Odontologia. Diário Oficial da União, Brasília, 4 mar. 2002. Seção 1, p.10.

COSTA, I.C.C.; UNFER, B.; OLIVEIRA, A.G.R.C.; ARCIERI, R.M.; SALIBA, N.A.; MIMAZ, S.A.S. Integração universidade-comunidade: análise das atividades extra-murais em Odontologia nas universidades brasileiras. Rev. CROMG, v.6, p.146-53, 2000.

FACULDADE DE ODONTOLOGIA - UFMG. Estágio Supervisionado em Odontologia: apresentação da disciplina. Belo Horizonte: Faculdade de Odontologia da UFMG, 2003. (mimeogr.).

FREIRE, P. Pedagogia da autonomia: saberes necessários à prática educativa. 29.ed. São Paulo: Paz e Terra, 2001.

GUIMARÃES ROSA, J. Manuelzão e Miguilim. 11.ed. São Paulo: Nova Fronteira, 2001.

HUDELSON, M.P. Qualitative research for health programs. Geneva: Division of Mental Health, 1994.

IYDA, M. Saúde bucal: uma prática social. In: BOTAZZO, C.; FREITAS, S.F.T. (Orgs.). Ciências sociais e saúde bucal: questões e perspectives. Bauru: Unesp, 1998. p.127-39.

KITZINGER, H. Introducing focus groups. In: MAYS, N.; POPE, C. Qualitative research in health care. London: BMJ Publishing Group, 1996. p.299-302.

MAMEDE, S.; PENAFORTE, J.; SCHMIDT, H.; CAPRARA, A.; TOMAZ, J.B.; SÁ, H. Aprendizagem baseada em problemas. Fortaleza: Hucitec, 2001. 
MASETTO, M.T. Processo de aprendizagem no ensino superior e suas conseqüências para a docência universitária. In: REUNIÃO DAASSOCIAÇÃO BRASILEIRA DE ENSINO ODONTOLÓGICO, 33, 1998, Fortaleza. Rev. ABENO, p.9-16, 1998.

MINAYO, M.C.S. O desafio do conhecimento: pesquisa qualitativa em saúde. 8.ed. São Paulo: Hucitec/ Abrasco, 2004.

PAIXÃO, H.H. A Odontologia sob o capital: o mercado de trabalho e a formação universitário-profissional do cirurgião dentista. 1979. Dissertação (Mestrado) - Faculdade de Educação, Universidade Federal de Minas Gerais, Belo Horizonte.

SANTA-ROSA, T.T.A. A influência do estágio supervisionado na formação de estudantes do curso de Odontologia da UFMG. 2005. Dissertação (Mestrado) - Faculdade de Odontologia, Universidade Federal de Minas Gerais, Belo Horizonte.

UNESCO-MEC. United Nations Educational, Scientific and Cultural Organization. Ministério da Educação e Cultura. Educação: um tesouro a descobrir. São Paulo: Cortez, 1999.

UNFER, B.; SALIBA, O. O cirurgião dentista do serviço público: formação, pensamento e ação. Rev. Bras. Odontol. Saúde Coletiva, v.2, n.2, p.45-51, 2001.

VARGAS, A.M.D.; PAIXÃO, H.H. Perda dentária e seu significado na qualidade de vida de adultos usuários de serviço público de saúde bucal do Centro de Saúde Boa Vista, em Belo Horizonte. Ciênc. Saúde Colet., v.10, n.4, p.1015-24, 2005.

VÍCTORA, C.G.; KNAUTH, D.R.; HASSEN; M.N.A. Pesquisa qualitativa em saúde: uma introdução ao tema. Porto Alegre: Tomo Editorial, 2000.

SANTA-ROSA, T.T.A.; VARGAS, A.M.D.; FERREIRA, E.F. El internado rural y la formación de los estudiantes del curso de Odontología de la UFMG, Universidad Federal de Minas Gerais, Brasil. Interface - Comunic., Saúde, Educ., v.11, n.23, p.451-66, set/dez 2007.

Este artículo muestra la influencia en la formación de estudiantes de Odontología de la UFMG a partir de la experiencia del Internado Rural (IR). Basándose en una metodología cualitativa, se recogieron los datos utilizando la técnica de grupos focales. Quince estudiantes que participaron de los grupos antes y después de concluir el curso constituyeron la muestra. En la evaluación de los datos surgieron cuatro temas: expectativas y realización del IR, servicio público de salud y comprensión del proceso salud-enfermedad. Se concluyó que el IR es encarado como una transición entre vida académica y mundo profesional; que el poco énfasis que se les da a las ciencias sociales y al servicio público de salud durante los períodos anteriores a la graduación dificultó la inserción de los estudiantes en el servicio de salud; que los estudiantes constataron con sorpresa las precarias condiciones de vida de la población y la existencia de servicios públicos de salud organizados y resolutivos en el nivel básico. Las experiencias vivenciadas en el IR despertaron hacia el atendimiento pautado en la acogida y en los cuidados a la salud.

PALABRAS CLAVE: Internado Rural. Educación en Odontología. Estudiantes de Odontología. 